\title{
Two Point Mutations on CYP51 Combined With Induced Expression of the Target Gene Appeared to Mediate Pyrisoxazole Resistance in Botrytis cinerea
}

\author{
Can Zhang', Muhammad Imran ${ }^{1}$, Min Liu', Zhiwen Li ${ }^{3}$, Huige Gao', Hongxia Duan', \\ Shunli Zhou ${ }^{1}$ and Xili Liü* \\ ${ }^{1}$ China Agricultural University, Beijing, China, ${ }^{2}$ State Key Laboratory of Crop Stress Biology for Arid Areas, Northwest A\&F \\ University, Yangling, China, ${ }^{3}$ Institute for the Control of Agrochemicals of Shaanxi Province, X'an, China
}

\section{OPEN ACCESS}

Edited by: Daisuke Hagiwara, University of Tsukuba, Japan

Reviewed by: Anne-Sophie Walker, INRA UR1290 Biologie et Gestion des Risques en Agriculture, France

Guojun Wang,

Florida Atlantic University,

United States

${ }^{*}$ Correspondence:

Xili Liu

seedling@nwafu.edu.cn

Specialty section: This article was submitted to Fungi and Their Interactions,

a section of the journal

Frontiers in Microbiology

Received: 23 February 2020 Accepted: 29 May 2020

Published: 30 June 2020

Citation:

Zhang C, Imran M, LiU M, Li Z,

Gao H, Duan H, Zhou S and Liu X (2020) Two Point Mutations on CYP51 Combined With Induced Expression of the Target Gene Appeared to Mediate Pyrisoxazole

Resistance in Botrytis cinerea.

Front. Microbiol. 11:1396. doi: 10.3389/fmicb.2020.01396
Botrytis cinerea is a destructive plant pathogenic ascomycete that causes serious pre- and post-harvest losses worldwide. The novel sterol $14 \alpha$-demethylase inhibitor (DMI) pyrisoxazole was recently registered for the control of tomato gray mold caused by $B$. cinerea in China. Baseline sensitivity of $110 \mathrm{~B}$. cinerea isolates collected from nine provinces in China to pyrisoxazole was demonstrated, with a mean $\mathrm{EC}_{50}$ of $0.057 \pm 0.029 \mu \mathrm{g} / \mathrm{ml}$. Eleven stable mutants resistant to pyrisoxazole were generated via UV irradiation (RU-mutants) and spontaneous selection (RS-mutants) of conidia. The efficacy of pyrisoxazole against the resistant mutants was significantly lower than that of the sensitive isolates. Most of the pyrisoxazole- resistant mutants were less fit than the sensitive isolates, with reduced sporulation, conidia germination, sclerotium production, and pathogenicity, which was confirmed by the competitive ability test. Positive cross-resistance was only observed between pyrisoxazole and the DMls tebuconazole and prochloraz, but not between pyrisoxazole and non-DMls iprodione, procymidone, diethofencarb, fluazinam, pyrimethanil, or fludioxonil. A two-point mutation, at G476S and K104E in the RU-mutants, and a one point mutation, M231T, in the RS-mutants, were detected in the CYP51 protein of the resistant mutants. When exposed to pyrisoxazole, the induced expression level of CYP51 increased in the resistant isolates as compared to sensitive ones. Molecular docking suggested that G476S and M231T mutations both led to the loss of electrostatic interactions between CYP51 and pyrisoxazole, while no change was found with the K104E mutation. Thus, two point mutations on CYP51 protein combined with induced expression of its target gene appeared to mediate the pyrisoxazole resistance of $B$ cinerea.

Keywords: Botrytis cinerea, pyrisoxazole, DMI, resistance, CYP51, point mutation, induced expression

\section{INTRODUCTION}

Gray mold, caused by the ascomycete Botrytis cinerea Pers.: Fr. [teleomorph: Botryotinia fuckeliana (de Bary) Whetzel], is one of the most destructive diseases of crops both pre- and post-harvest (Williamson et al., 2007; Kumari et al., 2014). It causes considerable losses in over 200 types of economically valuable vegetables, fruits, and ornamental plants including tomato, cucumber, 
eggplant, zucchini, strawberry, and grape (Williamson et al., 2007; Samuel et al., 2011; Liu et al., 2016). Cultivation of plants in greenhouses increases the risk of infection by $B$. cinerea because the presence of high humidity is especially favorable to the pathogen (Rosslenbroich and Stuebler, 2000; Elad et al., 2007). In China, the percentage of yield loss caused by $B$. cinerea gray mold in vegetable production can be over $60 \%$ in some severely infected regions (Si et al., 2004a,b).

Control of gray mold is based on integrated management strategies, including cultivar resistance, physical factors, and inoculum reduction. Nevertheless, chemical control remains the main approach for the management of $B$. cinerea diseases (Leroux, 2007; Hahn, 2014; Fan et al., 2017; Yin et al., 2018). Several site-specific fungicides with different modes of action are available for gray mold management, including methyl benzimidazole carbamates (MBCs), anilinopyrimidines (APs), dicarboximides (DCFs), quinone outside inhibitors (QoIs), succinate dehydrogenase inhibitors (SDHIs), and phenylpyrroles (PPs). Unfortunately, according to the Fungicide Resistance Action Committee (FRAC) ${ }^{1}$, B. cinerea has been categorized as a high-risk pathogen due to the development of fungicide resistance. Over the last 30 years worldwide, the resistance of $B$. cinerea to these types of fungicides was frequently reported soon after their introduction for gray mold control (Moyano et al., 2004; Myresiotis et al., 2007; Zhang et al., 2009; FernándezOrtuño et al., 2012; Chen et al., 2016; Yin et al., 2018). Resistance of $B$. cinerea often compromises the efficacy of fungicide and results in disease control failure. The most common disease management practice consists of alternation or tank mixtures of fungicides with different modes of action.

Sterol $14 \alpha$-demethylase inhibitors (DMIs) are a major group of systemic fungicides that exhibit broad spectra of antifungal activity. The continued and successful use of DMI fungicides, even with the emergence of resistance, justifies the development of new fungicides in this class (Chen et al., 2012). The novel fungicide pyrisoxazole (previous Development Code No. SYP-Z048), 3-[5-(4-chlorophenyl)-2,3dimethyl- 3-isoxazolidinyl] pyridine, is developed by the China Shenyang Sinochem Agrochemicals R\&D Co., Ltd. (Former: China Shenyang Research Institute of Chemical Industry) (Supplementary Figure S1; Chen et al., 2015). This fungicide belongs to the pyridine subgroup within the DMI class, like pyrifenox that also has been shown in Supplementary Figure S1 (FRAC). Pyrisoxazole has shown great promise for the control of a broad range of fungi (Liu et al., 2004; Si et al., 2004a,b). It has been officially registered for the control of tomato gray mold in China under the tradename Junsiqi in 2008 (China Pesticide Information Network) ${ }^{2}$, and is currently being developed for applications on other target pathogens, such as against Sclerotinia sclerotiorum in oilseed rape (Duan et al., 2018b).

Until now, no systematic information has been available on the risk and molecular mechanism(s) of pyrisoxazole resistance in B. cinerea. Only one study has reported pyrisoxazole sensitivity in isolates sampled from the Liaoning Province in China

${ }^{1}$ https://www.frac.info/

${ }^{2}$ http://www.chinapesticide.org.cn
(Zhu et al., 2016). Knowing the resistance basis of fungicides in pathogens is vital for disease management. The basis of resistance of DMI fungicides is most commonly conferred by (i) mutations in the CYP51 gene, (ii) increased expression of the CYP51 gene, or (iii) increased expression of membrane-bound transporters (Hayashi et al., 2001; Ma and Michailides, 2005; Kretschmer et al., 2009; Cools et al., 2013; Leroux and Walker, 2013). Pyrisoxazole resistance in Monilinia fructicola mutants was correlated with the presence of a mutation in the CYP51 gene that caused an amino acid change from tyrosine to phenylalanine at position 136 (Chen et al., 2012, 2015).

The objectives of this study were to (i) establish a baseline sensitivity of $B$. cinerea isolates from China to the DMI fungicide pyrisoxazole, (ii) generate and characterize pyrisoxazole-resistant mutants to assess the risk of $B$. cinerea developing resistance to pyrisoxazole, and (iii) explore molecular mechanisms that might be responsible for resistance to pyrisoxazole. Such data are essential for subsequent fungicide resistance monitoring programs, as we found two point mutations G476S and M231T in the target protein CYP51 as well as induced expression of the target gene both appeared to contribute to the resistance of B. cinerea to pyrisoxazole.

\section{MATERIALS AND METHODS}

\section{Isolates and Culture Conditions}

A total of $110 \mathrm{~B}$. cinerea isolates were isolated from diseased tomato leaves or fruits between 2008 and 2012 from nine provinces in northern, central, and southern China where there was no history of pyrisoxazole usage (Supplementary Table S1). After purification by single-spore isolation, the isolates were firstly identified as $B$. cinerea and its closely related species by polymerase chain reaction (PCR) using a previously reported primer pair $\mathrm{Bc}-\mathrm{f} / \mathrm{Bc}-\mathrm{r}$ designed on the basis of a sequence-characterized amplified region marker (Fan et al., 2015). Then, a PCR-restriction fragment length polymorphism (RFLP) analysis of the 18S/28S rRNA intergenic spacer (IGS) region with primers IGS1a and IGS1b was performed to distinguish B. cinerea and B. pseudocinerea, and the PCR product was digested with HinfI as previously described (Kretschmer and Hahn, 2008). All isolates were cultured in darkness on potato dextrose agar (PDA) plates at $20^{\circ} \mathrm{C}$. For long-term storage, mycelia of each isolate were maintained in $5 \mathrm{ml}$ plastic tubes containing PDA medium slants under mineral oil at $14^{\circ} \mathrm{C}$.

\section{Sensitivity of $B$. cinerea Isolates to Pyrisoxazole}

Pyrisoxazole was standard grade and kindly provided by China Shenyang Sinochem Agrochemicals R\&D Co., Ltd. The pyrisoxazole sensitivity of $110 \mathrm{~B}$. cinerea single-spore field isolates was determined by calculating the $50 \%$ inhibitory dose $\left(\mathrm{EC}_{50}\right.$ value) on fungicide-amended PDA in Petri plates according to the method previously described in Cai et al. (2015). The fungicide concentrations are shown in Supplementary Table S2. The final concentration of DMSO solvent in the medium was $0.1 \%$. After incubation for 3 days in darkness at $20^{\circ} \mathrm{C}$, each colony 
diameter (minus $5 \mathrm{~mm}$ for the inoculated plug) was measured in two perpendicular directions. Each combination of isolate and fungicide was represented by three replicate plates, and the experiment was performed twice.

\section{Generation of Pyrisoxazole-Resistant Mutants}

Ultraviolet (UV) irradiation and spontaneous selection of B. cinerea mycelium and conidia on pyrisoxazole-amended media were used in attempts to generate mutants. For the generation of UV irradiation mutants from mycelium, Petri dishes containing 3-day-old actively growing colonies of four DMI-sensitive isolates with different geographical origins and good fitness (S11, H9, T39, NJ10) were exposed for 40-50 min to a $254 \mathrm{~nm}$ UV light source placed $10 \mathrm{~cm}$ above the cultures. The exposed colonies were incubated in darkness for $1 \mathrm{~h}$, after which mycelial plugs ( $5 \mathrm{~mm}$ in diameter) were excised from the dishes and transferred to PDA plates amended with pyrisoxazole at $1.0 \mu \mathrm{g} / \mathrm{ml}$ (minimal inhibitory concentration). After incubation at $20^{\circ} \mathrm{C}$ for $7-10$ days in darkness, actively growing colonies were transferred to fresh fungicide-free PDA. Five days later, mycelial plugs from the colony periphery were transferred to PDA medium amended with pyrisoxazole at $1.0 \mu \mathrm{g} / \mathrm{ml}$ (the discriminatory concentration) to confirm resistance.

To induce conidia production, mycelial plugs $(5 \mathrm{~mm})$ excised from the margin of a 3-day-old PDA colony were placed upside-down on carrot agar medium (CA; $200 \mathrm{~g}$ of carrot, $15 \mathrm{~g}$ of agar, and distilled water to $1 \mathrm{~L}$ ). After a $14 \mathrm{~h}$ of light and $10 \mathrm{~h}$ of darkness for 5-7 days, the conidia were harvested, suspended in $1 \mathrm{ml}$ of sterile water, then treated with UV light $(20 \mathrm{~W}, 254 \mathrm{~nm})$ at $10 \mathrm{~cm}$ vertical distance for $45 \mathrm{~s}$ at $20^{\circ} \mathrm{C}$, followed by $1 \mathrm{~h}$ of incubation in darkness to avoid light repair of DNA damage. The conidia were evenly distributed on CA medium amended with pyrisoxazole at $1.0 \mu \mathrm{g} / \mathrm{ml}$. After 10 days of incubation, developing colonies were transferred to fresh fungicide-free PDA and then transferred to PDA medium amended with pyrisoxazole at 1.0 $\mu \mathrm{g} / \mathrm{ml}$ to confirm resistance.

For the generation of spontaneous mutants, the same procedure as above was used but without UV irradiation. The determination of $\mathrm{EC}_{50}$ values for putative mutants was conducted as described previously. Each isolate was tested in triplicate and the experiment was repeated once. The mutation frequency as a percentage was calculated as the number of mutants/total number of treated conidia or mycelial plugs $\times 100$; the resistance factor (RF) was calculated according to the formula $\mathrm{EC}_{50}$ value of the mutant/ $\mathrm{EC}_{50}$ value of its sensitive parent.

\section{Investigation of Control Efficacy Using Detached Leaf Assays}

Four isolates, including two sensitive parental isolates (S11 and NJ10) and two resistant isolates (RU11-7 and RS10-1), were used to assess fungicide performance on treated leaves, as described previously (Zhang et al., 2019). Briefly, commercial-variety tomato (cv. BeiBei) leaves of similar size with no fungicide application were rinsed with water for $1 \mathrm{~min}$, and air-dried. The detached leaves were sprayed to run-off with two concentrations
(50 or $100 \mu \mathrm{g} / \mathrm{ml}$ ) near the label rate of pyrisoxazole (75-150 $\mu \mathrm{g} / \mathrm{ml}$ ) diluted in Tween-80 water, respectively. Control leaves were sprayed with sterile distilled Tween- 80 water. Leaves were allowed to dry overnight at $20^{\circ} \mathrm{C}$. Mycelial plugs $(5 \mathrm{~mm}$ in diameter) taken from the margins of the actively growing colony were placed upside down on the leaves. After inoculation, the plastic boxes were sealed with plastic bags to keep the relative humidity near $100 \%$. After 5 days at $20^{\circ} \mathrm{C}$ with $12 \mathrm{~h}$ of light and $12 \mathrm{~h}$ of darkness, the lesion area on each leaf was measured. The experiment was conducted twice independently. Control efficacy was calculated according to the following formula: Control efficacy $=$ ([lesion area with water application lesion area with fungicide treatment] / lesion area with water application) $\times 100 \%$.

\section{Stability of Pyrisoxazole Resistance in Mutants}

Mycelial plugs taken from the periphery of actively growing colonies were transferred a total of 10 times to fresh, fungicide-free PDA medium. $\mathrm{EC}_{50}$ values for pyrisoxazole were determined before the transfer and after the 5th and 10th transfer. Each mutant was evaluated in triplicate, and the entire experiment was conducted twice.

\section{Mycelial Growth Rate Over a Series of Temperatures}

Mycelial plugs (5 $\mathrm{mm}$ in diameter) of each isolate were transferred from the leading edge of an actively growing colony to PDA dishes and incubated in darkness at $4,20,25,28$, or $39^{\circ} \mathrm{C}$. Colony diameter was measured after 2 days of incubation. Each combination of isolate or mutant and temperature was represented by three replicate plates, and the experiment was conducted twice.

\section{Conidia Production and Germination Rate in vitro}

Conidia were induced as described in the previous section and harvested by rinsing the sporulating colony in each plate with $10 \mathrm{ml}$ of a $0.1 \%$ aqueous glucose solution. The number of conidia in the suspension were counted with a hemacytometer and a microscope. To determine the rate of germination, the conidial suspension was adjusted to $10^{5}-10^{6}$ conidia/ml and $50 \mu \mathrm{l}$ of the suspension was spread onto depression slides placed on top of wet filter paper in a petri dish. The depression slides were incubated at $20^{\circ} \mathrm{C}$ for $6 \mathrm{~h}$ in darkness. In total, 200 conidia were assessed per isolate for germination ability under a microscope. Each isolate was tested in triplicate and the entire experiment was repeated once.

\section{Pathogenicity, Conidial Production, and Germination Rate in vivo}

Pathogenicity of $B$. cinerea was determined on detached leaves of "BeiBei" as described above, but without fungicide treatment. Controls consisted of leaves that were punctured and then inoculated with a sterile agar plug or distilled water. After 5 days 
at $20^{\circ} \mathrm{C}$ with $12 \mathrm{~h}$ of light and $12 \mathrm{~h}$ of darkness, the lesion area on each leaf was measured. The experiments were performed twice.

Conidia production in vivo was measured by inoculating leaves as described in the previous paragraph. After incubation at $20^{\circ} \mathrm{C}$ for another $7-10$ days, the number of conidia and the germination rate were determined in a $0.1 \%$ aqueous glucose solution. Each isolate was tested in triplicate and the in vivo sporulation experiments were performed twice.

\section{Sclerotia Production}

For comparison of sclerotia production, an agar plug cut from the edge of a 3-day-old colony on PDA was placed in the center of a $9 \mathrm{~cm}$ diameter Petri dish. After 20 days at $20^{\circ} \mathrm{C}$ in darkness, sclerotia were removed from the cultures and dried to a constant weight at $50^{\circ} \mathrm{C}$ for $16 \mathrm{~h}$. Sclerotia production was expressed as sclerotia dry mass per Petri dish. Each isolate or mutant was represented by three replicate Petri dishes, and the experiment was conducted twice.

\section{Competitive Ability}

Competitive ability was determined for five combinations of the sensitive parental isolates (S) and their resistant mutants (R): S11 versus RU11-7, S11 versus RU11-21, NJ10 versus RS10-1, NJ10 versus RS10-4, and NJ10 versus RS10-5. Each combination consisted of three ratios of the $S$ and $R$ isolates (9R:1S, 5R:5S, and 1R:9S), which were prepared by mixing conidial suspensions of the pyrisoxazole sensitive isolates and the corresponding resistant mutants. Conidial suspensions were prepared as described earlier, and the final concentration for each was adjusted to $1 \times 10^{5} / \mathrm{ml}$ with the aid of a hemacytometer and microscope. A $100 \mu \mathrm{l}$ volume of each of the resulting conidial suspensions was spread on a CA plate, and the cultures were grown, and conidia were harvested as described earlier. This procedure was repeated five times (five subcultures). After the 1st, 3rd, and 5th subculture, 70 single conidial isolates were obtained and transferred to PDA plates amended with $1 \mu \mathrm{g} / \mathrm{ml}$ pyrisoxazole. Isolates that were able to grow on the plates amended with the discriminatory concentration of pyrisoxazole were considered resistant, and those that could not were considered sensitive. The ratios of the resistant and sensitive isolates obtained after subculture on CA were calculated and compared with the original ratios. This experiment was performed twice.

\section{Cross-Resistance}

The pyrisoxazole-resistant mutants and their parents were exposed to two DMIs (tebuconazole, and prochloraz) belonging to different chemical groups, and five other fungicides of different modes of action (iprodione, procymidone, diethofencarb, fluazinam, pyrimethanil, and fludioxonil). The $\mathrm{EC}_{50}$ values for each isolate/fungicide combination were determined using the aforementioned mycelial growth inhibition method, except that glucose-gelatin-agar medium $(0.4 \%$ glucose, $0.4 \%$ gelatin, $0.177 \%$ $\mathrm{K}_{2} \mathrm{HPO}_{4}, 0.036 \% \mathrm{MgSO}_{4} \cdot 7 \mathrm{H}_{2} \mathrm{O}$, and $1.2 \%$ agar) was used for pyrimethanil (Birchmore et al., 1996), and salicylhydroxamic acid was added to the azoxystrobin-amended medium with a final concentration of $100 \mu \mathrm{g} / \mathrm{ml}$ to inhibit the alternative respiration pathway (Bardas et al., 2010). The concentrations used for each fungicide are provided in Supplementary Table S2. Each treatment had three replicate plates, and the experiment was conducted twice.

\section{Cloning and Sequencing of the BcCYP51 Gene}

Genomic DNA was extracted from mycelium, as described previously (Chi et al., 2009). The complete BcCYP51 gene was amplified with primer pair BcCYP51-F and BcCYP51-R as described previously (Albertini et al., 2002). The amplified $B c C Y P 51$ full-length fragments were purified using the EasyPure Quick Gel Extraction Kit (TransGen, Beijing, China) and were cloned into the pEASY-T1 simple plasmid (TransGen, Beijing, China) according to the manufacturer's recommendations. The vector inserted into Escherichia coli was sequenced (Sunbiotech Co., Beijing) using vector primers M13F (5'-ACTGGCCGTCGTTTTAC-3') and M13R (5'GTCCTTTGTCGATACTG-3'). DNA sequences were analyzed with DNAMAN software (Lynnon BioSoft, Quebec, Canada).

\section{Determination of the Expression Level of CYP51}

Each isolate was grown in $150 \mathrm{ml}$ Erlenmeyer flasks containing $80 \mathrm{ml}$ of PDB liquid medium. After 3 days at $20^{\circ} \mathrm{C}$ on a rotary shaker at $150 \mathrm{rpm}$, pyrisoxazole ( $\mathrm{EC}_{50}$ value for each isolate) was added to three of the six flasks for each isolate. After $24 \mathrm{~h}$, mycelia were harvested by vacuum filtration for RNA extraction. Total RNA was extracted by the SV Total RNA Isolation Kit (Promega, Beijing, China), and cDNA was synthesized using the PrimeScript RT Reagent Kit with gDNA Eraser (Takara, Beijing, China), following the manufacturer's instructions.

The expression level of the target genes was quantified by quantitative real-time PCR (qRT-PCR), which was performed with an ABI7500 sequence detection system (Applied Biosystems, United States). qRT-PCR was conducted in a $20 \mu \mathrm{l}$ reaction volume with the SYBR Premix Dimer Eraser Kit (Takara, Beijing, China). The following program were used for the qRT-PCR analysis by three biological replications: $95^{\circ} \mathrm{C}$ for $30 \mathrm{~s}$, followed by 40 cycles of $95^{\circ} \mathrm{C}$ for $5 \mathrm{~s}, 60^{\circ} \mathrm{C}$ for $30 \mathrm{~s}$, and $72^{\circ} \mathrm{C}$ for $34 \mathrm{~s}$. Primers used for qRT-PCR were CYP51-QF/QR (5'-ATTTGGTGCTGGCAGACATAGA-3'; $5^{\prime}$ GTGAATAAACTTGCGTAATCG GTA-3') for the BcCYP51 gene and Actin-QF/QR (5'-CTGGTCGTGATTT GACTGATTA$3^{\prime} ; 5^{\prime}$-GATTGACTGGCGGT TTGG-3') for the reference gene actin. The relative quantities (RQs) of products were calculated using the $2^{-\Delta \Delta C t}$ method (Livak and Schmittgen, 2001). Three independent experiments were conducted.

\section{Molecular Docking Analysis}

Bioinformatic analysis was used to investigate the molecular docking of pyrisoxazole with the BcCYP51 protein. The crystal structure of 5HS1, a CYP51 protein from the yeast Saccharomyces cerevisiae bound with voriconazole, was retrieved from the Protein Data Bank and used in the current study. Sequence alignment by DNAMAN software indicated that the CYP51 amino acid residues of $S$. cerevisiae showed about $45 \%$ sequence 
identity with that of $B$. cinerea. The crystal structure 5HS1 was a suitable template for studying the binding conformation of pyrisoxazole with the BcCYP51 protein.

The modeling structure of $B$. cinerea was obtained by using the template 5HS1 and the online Swiss-model software ${ }^{3}$. The binding cavity was predicted by a ligand mode for voriconazole complexed in CYP51 by the SYBYL 7.3 software program. The Biopolymer-Replace Sequence subset from the Sybyl X2.0 software package was used to produce site-directed mutations at residues K104, G476, and M231, respectively. The Tripos force field with Gasteiger-Marsili charges was used for energy minimization. The molecular conformations of pyrisoxazole were constructed by Sketch mode and were optimized using the Tripos force field and Gasteiger-Hückel charge. The Surflex-Dock of SYBYL 7.3 was used for the molecular docking modeling (Jain, 2003). The binding cavity was set as "ligand," and the total score was used to evaluate the binding affinity between ligand and protein (Jain, 1996). All molecular modeling between the putative $B$. cinerea CYP51 proteins with ligand was conducted on the Silicon Graphics (SGI) Fuel Workstation (Silicon Graphics International Corp., CA, United States).

\section{Statistical Analysis}

Data were analyzed by SPSS software (ver. 21.0) based on an unpaired Student's $t$-test. An asterisk indicates significant differences with the $P$-values marked $\left({ }^{*} P<0.05\right.$; ${ }^{*} P<0.01$, $\left.{ }^{* * *} P<0.001\right)$. Cross-resistance between two fungicides was analyzed using Spearman's rank correlation coefficient with log-transformed $\mathrm{EC}_{50}$ values.

\section{RESULTS}

\section{Baseline Sensitivity of $B$. cinerea in China to Pyrisoxazole}

The $\mathrm{EC}_{50}$ values required for pyrisoxazole to inhibit mycelial growth of $B$. cinerea field isolates collected from nine provinces in China ranged from 0.020 to $0.166 \mu \mathrm{g} / \mathrm{ml}$, with a mean $\mathrm{EC}_{50}$ of $0.057 \pm 0.029 \mu \mathrm{g} / \mathrm{ml}$ (Figure 1). The ratio of the maximum $\mathrm{EC}_{50}$ to the minimum $\mathrm{EC}_{50}$ was 8.3 . The range and mean of $\mathrm{EC}_{50}$ values in different populations are listed in Supplementary Table S1. The narrow range and low $\mathrm{EC}_{50}$ values of the $B$. cinerea isolates indicate no preexisting pyrisoxazole resistance.

\section{Generation of Pyrisoxazole-Resistant Mutants}

No mutants were obtained from UV irradiation and spontaneous selection of mycelium. Six resistant mutants, designated as RU11-1, RU11-5, RU11-7, RU11-12, RU11-15, and RU11-21, were obtained from conidia of parental wild-type isolate S11 treated with UV light. Five mutants, designated as RS10-1 to RS10-5, were obtained from spontaneous selection from the conidia of parental isolate $\mathrm{NJ10} . \mathrm{EC}_{50}$ values of the mutants from UV irradiation ranged from 0.293 to $0.565 \mu \mathrm{g} / \mathrm{ml}$,

${ }^{3}$ https://www.swissmodel.expasy.org/

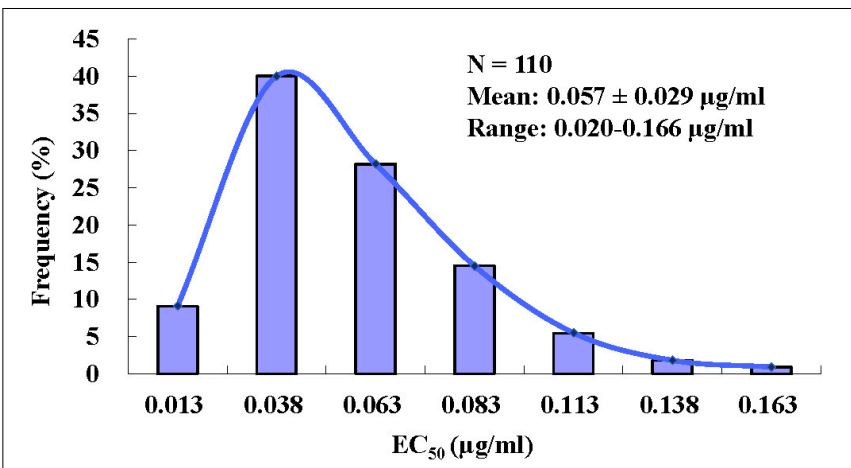

FIGURE 1 | Frequency distribution of effective concentrations for 50\% growth inhibition $\left(E_{50}\right)$ of pyrisoxazole against 110 Botrytis cinerea isolates.

with corresponding resistance factors of 4.7-9.1 (Table 1). The mutation frequency from UV irradiation of conidia was $6.5 \times 10^{-9} \cdot \mathrm{EC}_{50}$ values of the mutants from spontaneous selection of conidia ranged from 0.337 to $0.453 \mu \mathrm{g} / \mathrm{ml}$ with corresponding resistance factors of 7.6-10.1 (Table 1). The average mutation frequency from spontaneous selection of conidia was $5.0 \times 10^{-9}$.

\section{Detached Leaf Assays}

All isolates were able to infect and develop lesions on tomato leaves without fungicide treatment. Lesion development of DMI-sensitive isolates (S11 and NJ10) or resistant isolates (RU11-7 and RS10-1) was decreased on leaves sprayed with pyrisoxazole, compared with the control treatment. However, the control efficacy for two resistant isolates with the lowest

TABLE 1 | Stability and level of pyrisoxazole resistance of two groups of Botrytis cinerea mutants and their parental isolates, S11 and NJ10, after the 1st, 5th, and 10th subculture on fungicide-free medium.

\begin{tabular}{|c|c|c|c|c|c|c|c|}
\hline \multirow[t]{2}{*}{ Isolate $^{a}$} & \multicolumn{3}{|c|}{$\mathrm{EC}_{50}(\mu \mathrm{g} / \mathrm{ml})$} & \multicolumn{3}{|c|}{$\mathbf{R F}^{\mathbf{b}}$} & \multirow[t]{2}{*}{$\mathrm{FSC}^{\mathrm{C}}$} \\
\hline & 1st & 5 th & 10th & 1st & 5th & 10th & \\
\hline S11 & 0.062 & 0.055 & 0.057 & - & - & - & - \\
\hline RU11-3 & 0.545 & 0.375 & 0.465 & 8.8 & 6.8 & 8.2 & 0.9 \\
\hline RU11-5 & 0.310 & 0.268 & 0.350 & 5.0 & 4.9 & 6.1 & 1.2 \\
\hline RU11-7 & 0.293 & 0.229 & 0.342 & 4.7 & 4.2 & 6.0 & 1.3 \\
\hline RU11-12 & 0.326 & 0.313 & 0.353 & 5.3 & 5.7 & 6.2 & 1.2 \\
\hline RU11-15 & 0.438 & 0.313 & 0.374 & 7.1 & 5.7 & 6.6 & 0.9 \\
\hline RU11-21 & 0.565 & 0.455 & 0.417 & 9.1 & 8.3 & 7.3 & 0.8 \\
\hline NJ10 & 0.045 & 0.049 & 0.046 & - & - & - & - \\
\hline RS10-1 & 0.337 & 0.316 & 0.355 & 7.6 & 6.4 & 7.7 & 1.0 \\
\hline RS10-2 & 0.401 & 0.379 & 0.331 & 8.9 & 7.7 & 7.2 & 0.8 \\
\hline RS10-3 & 0.385 & 0.418 & 0.417 & 8.6 & 8.5 & 9.1 & 1.1 \\
\hline RS10-4 & 0.358 & 0.327 & 0.327 & 8.0 & 6.7 & 7.1 & 0.9 \\
\hline RS10-5 & 0.453 & 0.440 & 0.433 & 10.1 & 9.0 & 9.4 & 0.9 \\
\hline
\end{tabular}

as11 and NJ10 correspond to the wild-type parental isolates. ${ }^{b} R F=$ resistance factor, the radio of the $\mathrm{EC}_{50}$ of the fungicide-resistant mutant to that of its wild-type parent. ${ }^{C} F S C=$ factor of sensitivity change, the radio of $R F$ values for $E C_{50}$ at the 10 th to the 1 st transfer. 
resistance factors was about $20 \%$ lower than that for the sensitive isolates at the two tested fungicide concentrations (Figure 2). The results demonstrated that there was a significant difference $(P<0.05)$ in control efficacy between sensitive and resistant isolates, indicating that reduced sensitivity of $B$. cinerea isolates to pyrisoxazole did occur.

\section{Resistance Level and Stability}

To determine the fitness of pyrisoxazole-resistant mutants, the level of pyrisoxazole resistance of the mutants was measured,

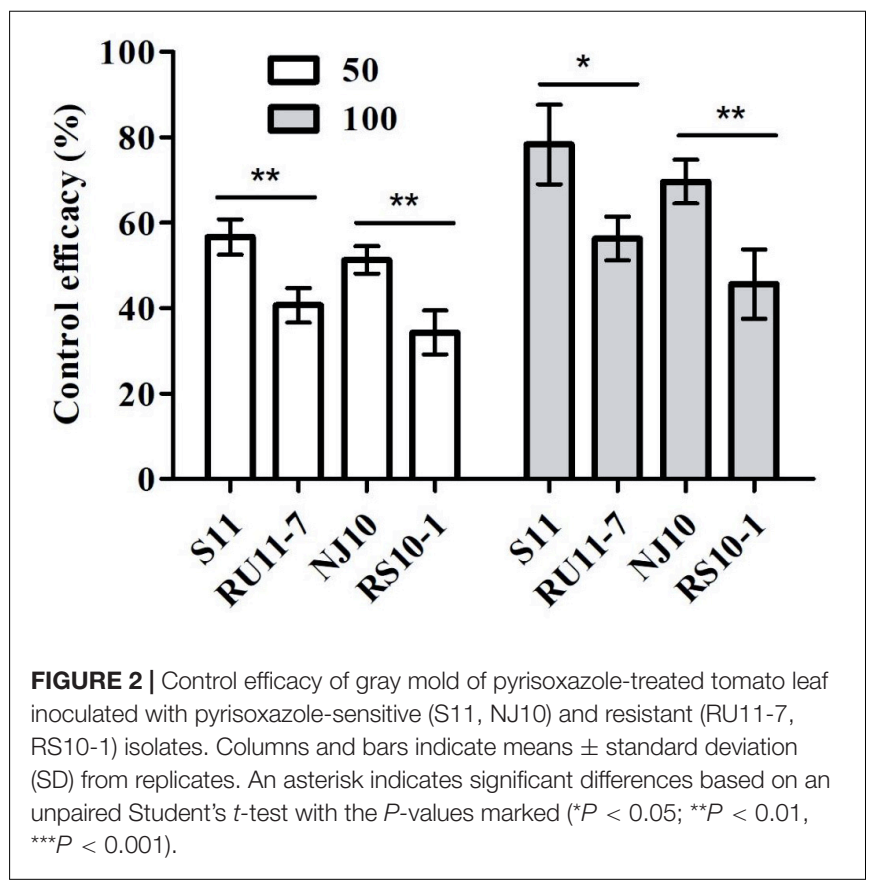

and the RF values (resistance factor, the ratio of the $\mathrm{EC}_{50}$ value of a resistant mutant to that of its parent) was determined. After 10 transfers on fungicide-free PDA, the FSC values (factor of sensitivity change, the ratio of RF values at the 10th to the 1 st transfer) ranged from 0.8 to 1.3 , indicating that resistance was stable.

\section{Colony Growth as Affected by Temperature}

For all of the pyrisoxazole-resistant mutants and their parental isolate of $B$. cinerea, the optimal temperature for mycelial growth was $20^{\circ} \mathrm{C}$ (Table 2). Most mutants grew at the same rate as their parental isolates at all the tested temperatures, except RU11-3 and RU11-21: these grew slower than their parental isolate S11 at 20,25 , and $28^{\circ} \mathrm{C}$ (Table 2). All isolates of $B$. cinerea did not grow at $39^{\circ} \mathrm{C}$.

\section{Most Resistant Mutants Experienced Fitness Penalty}

The average mycelial growth rate did not significantly differ for most pyrisoxazole-resistant mutants compared to the parental wild-type isolate, except for RU11-3 and RU11-21 (Table 3). Spore production was significantly lower for the mutants than for their parents except for RU11-21 and RS10-1, regardless of whether produced in vitro or in vivo (Table 3 ). All the RU-mutants had a reduced conidia germination rate, and the RS-mutants exhibited similar germination rates to that of the wild-type isolate in vivo (Table 3). Sclerotium production was significantly reduced in the RU-mutants but was higher in the RS-mutants except for RS10-1 (Table 3). The lesion area produced on detached tomato leaf was significantly reduced in the mutants compared to the parental wild-type isolate (Table 3).

TABLE 2 | Effect of temperature on the mycelial growth of resistant mutants of Botrytis cinerea and their wild-type parents on PDA without fungicide.

\begin{tabular}{|c|c|c|c|c|c|}
\hline \multirow[t]{2}{*}{ Isolate $^{a}$} & \multicolumn{5}{|c|}{ Colony diameter $(\mathrm{mm})^{\mathrm{b}}$} \\
\hline & $4^{\circ} \mathrm{C}$ & $20^{\circ} \mathrm{C}$ & $25^{\circ} \mathrm{C}$ & $28^{\circ} \mathrm{C}$ & $39^{\circ} \mathrm{C}^{\mathrm{c}}$ \\
\hline S11 & $0.6 \pm 0.1$ & $4.1 \pm 0.1$ & $3.8 \pm 0.2$ & $2.1 \pm 0.1$ & - \\
\hline $\mathrm{RU11-3}$ & $0.6 \pm 0.1$ & $3.7 \pm 0.2^{*}$ & $3.1 \pm 0.2^{\star \star}$ & $1.6 \pm 0.1^{\star \star}$ & - \\
\hline$R \cup 11-5$ & $0.4 \pm 0.0$ & $4.2 \pm 0.1$ & $3.7 \pm 0.2$ & $1.8 \pm 0.1$ & - \\
\hline RU11-7 & $0.4 \pm 0.1$ & $4.0 \pm 0.1$ & $3.1 \pm 0.1^{\star}$ & $1.8 \pm 0.2$ & - \\
\hline$R \cup 11-12$ & $0.5 \pm 0.0$ & $4.2 \pm 0.1$ & $3.8 \pm 0.2$ & $1.9 \pm 0.2$ & - \\
\hline$R \cup 11-15$ & $0.4 \pm 0.1$ & $4.0 \pm 0.1$ & $4.0 \pm 0.2$ & $1.8 \pm 0.1$ & - \\
\hline $\mathrm{RU11-21}$ & $0.3 \pm 0.0^{\star}$ & $3.5 \pm 0.2^{\star \star}$ & $3.1 \pm 0.2^{\star \star}$ & $1.5 \pm 0.1^{\star \star}$ & - \\
\hline NJ10 & $0.6 \pm 0.0$ & $4.2 \pm 0.1$ & $3.6 \pm 0.2$ & $2.2 \pm 0.1$ & - \\
\hline RS10-1 & $0.4 \pm 0.1$ & $4.2 \pm 0.2$ & $3.5 \pm 0.2$ & $1.9 \pm 0.1$ & - \\
\hline RS10-2 & $0.4 \pm 0.0$ & $4.2 \pm 0.1$ & $3.7 \pm 0.2$ & $1.9 \pm 0.1$ & - \\
\hline RS10-3 & $0.5 \pm 0.1$ & $4.0 \pm 0.1$ & $3.4 \pm 0.3$ & $1.8 \pm 0.2$ & - \\
\hline RS10-4 & $0.4 \pm 0.0$ & $4.1 \pm 0.1$ & $3.7 \pm 0.2$ & $1.9 \pm 0.2$ & - \\
\hline RS10-5 & $0.4 \pm 0.1$ & $4.0 \pm 0.2$ & $3.7 \pm 0.3$ & $1.8 \pm 0.1$ & - \\
\hline
\end{tabular}

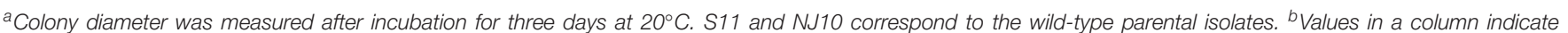
means $\pm S D$. An asterisk indicates significant differences based on an unpaired Student's $t$-test with the $P$-values marked $\left({ }^{*} P<0.05 ; * * P<0.01\right.$, $\left.* * * P<0.001\right)$. c"-"means the isolates could not grow at $39^{\circ} \mathrm{C}$. 
TABLE 3 | Comparison of fitness parameters for resistant Botrytis cinerea mutants and their wild-type parental isolatea .

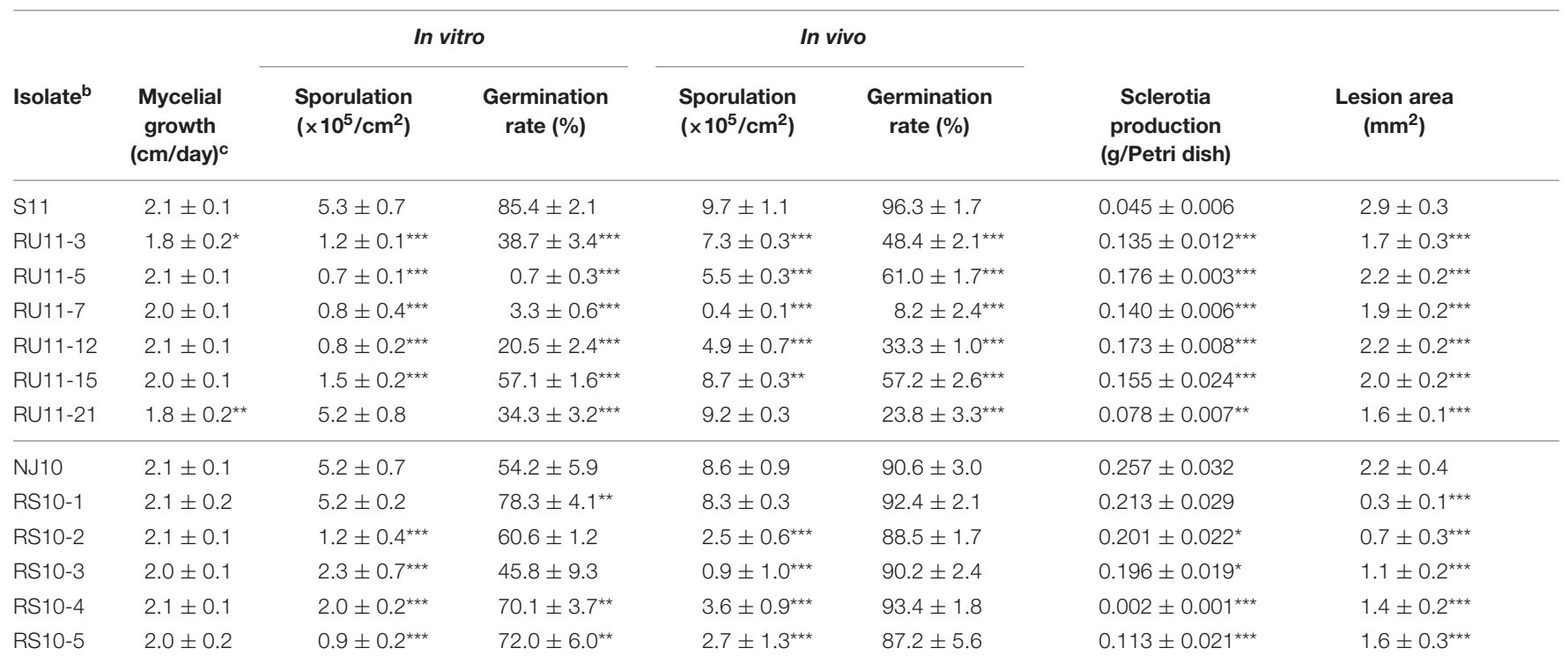

aValues in a column indicate means \pm standard deviation (SD). An asterisk indicates significant differences based on an unpaired Student's t-test with the P-values marked $\left({ }^{*} P<0.05 ;{ }^{* *} P<0.01,{ }^{* * *} P<0.001\right) .{ }^{b} S 11$ and $N 110$ correspond to the wild-type parental isolates. ${ }^{\circ}$ Growth rate was determined at the optimum temperature of $20^{\circ} \mathrm{C}$.

\section{Competitive Ability}

The observed frequency of pyrisoxazole-resistant isolates was less than the expected frequency in the combinations S11 versus RU11-7, S11 versus RU11-21, and NJ10 versus RS10-4 regardless of whether it was after the 1st, 3rd, or the 5th transfers (Figures 3A,B,D). For the NJ10 versus RS10-5 combination, the drop in the observed frequency of pyrisoxazole-resistant isolates occurred after the 3rd transfer (Figure 3E). However, RS10-1 showed a higher competitive ability than its parent NJ10 as indicated in Figure 3C. The results indicated that most of the pyrisoxazole-resistant isolates were less fit than the sensitive wild-type isolates, except RS10-1.

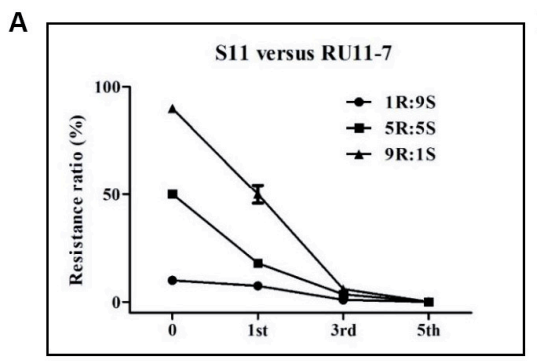

C

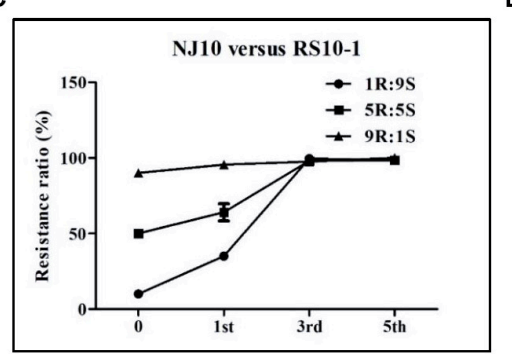

D

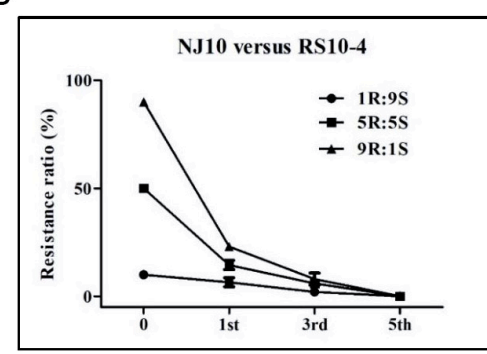

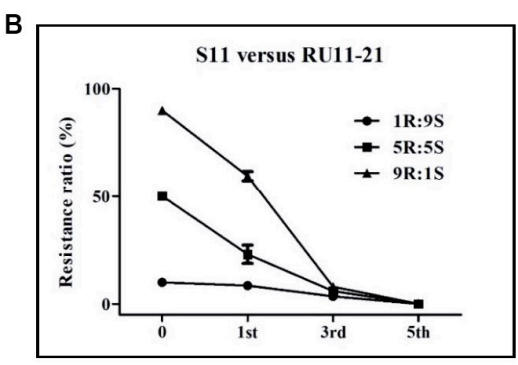

E

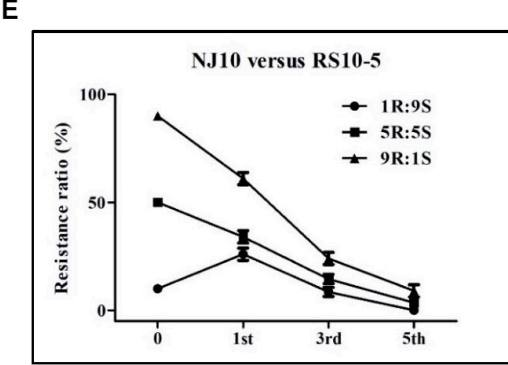

FIGURE 3 | Competition between pyrisoxazole-sensitive and resistant isolates of Botrytis cinerea as indicated by the resistance ratios after 1st, 3rd, and 5th subcultures on agar medium. Five combinations of the sensitive parental isolates $(S)$ and their resistant mutants (R) were determined: (A-E) representing S11 versus RU11-7, S11 versus RU11-21, NJ10 versus RS10-1, NJ10 versus RS10-4, and NJ10 versus RS10-5, respectively. Each combination consisted of three ratios of the $S$ and $R$ isolates (9R:1S, 5R:5S, and 1R:9S), which were prepared by mixing conidia suspensions of the pyrisoxazole-sensitive isolates and the corresponding resistant mutants. 

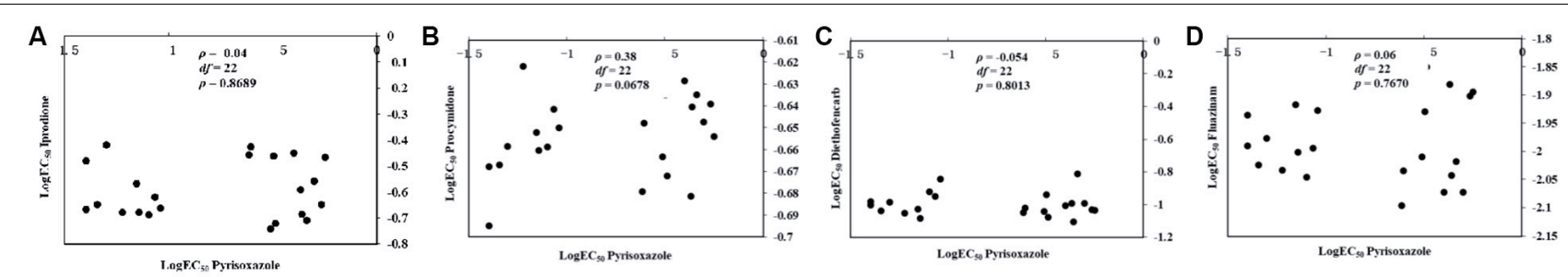

E

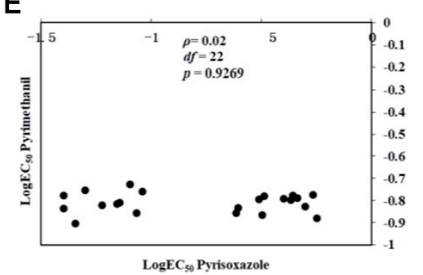

$\mathbf{F}$

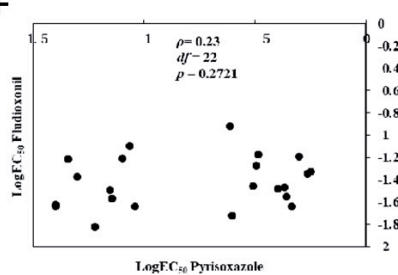

$\mathbf{G}$

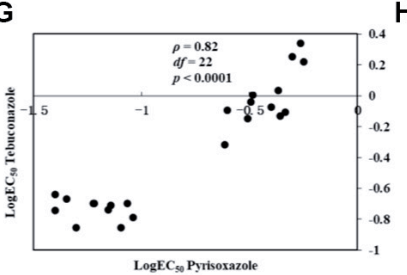

$\mathrm{H}$

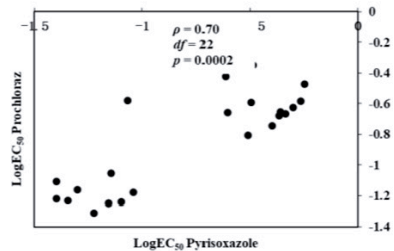

FIGURE 4 | Cross-resistance between pyrisoxazole and (A) iprodione, (B) procymidone, (C) diethofencarb, (D) fluazinam, (E) pyrimethanil, (F) fludioxonil, (G) tebuconazole, or $\mathbf{( H )}$ prochloraz by rank correlation analysis. Data shown in logarithmic values of effective concentrations for $50 \%$ mycelial growth inhibition (log $\mathrm{EC}_{50}$ ) among Botrytis cinerea for fungicide combinations.

A
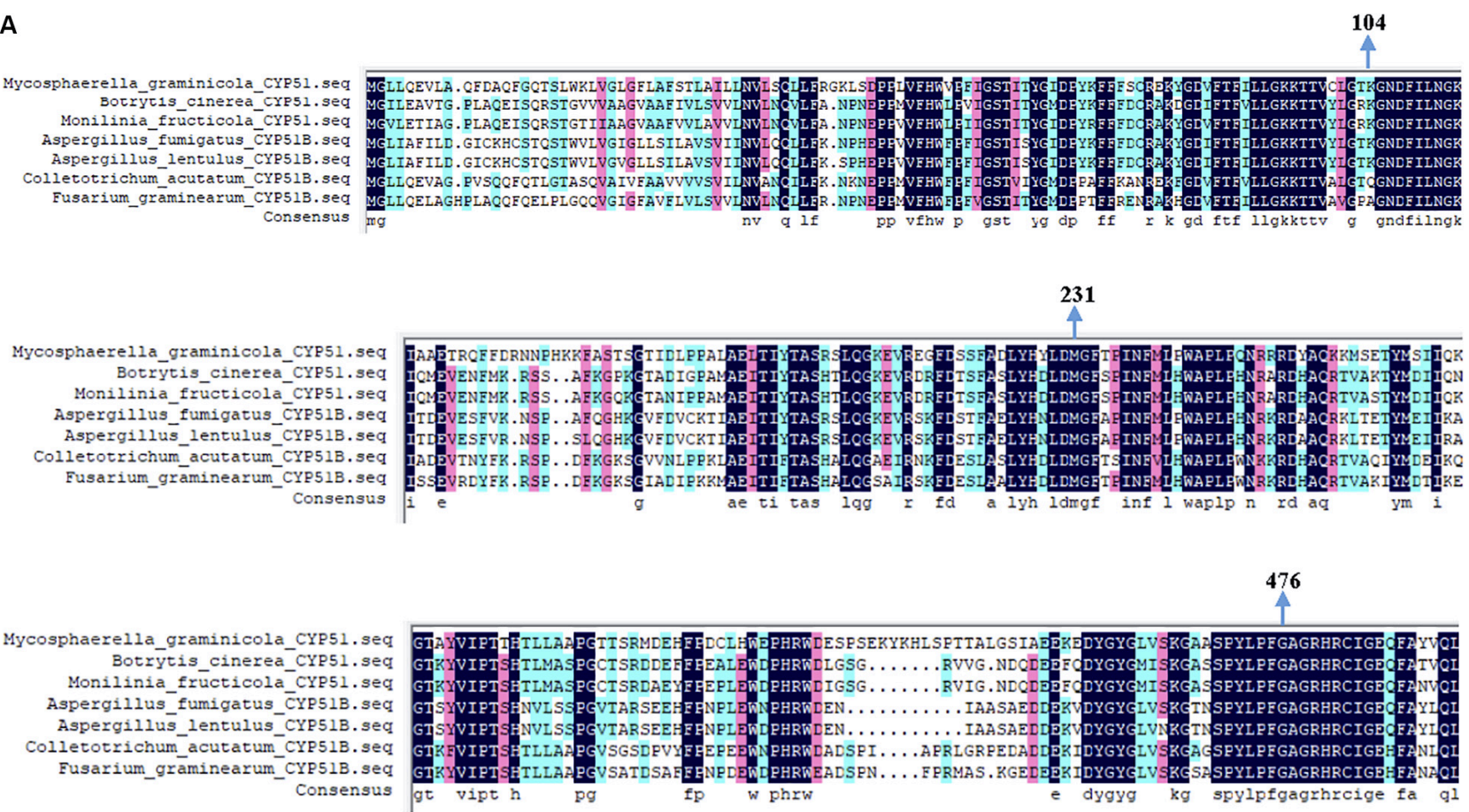

B

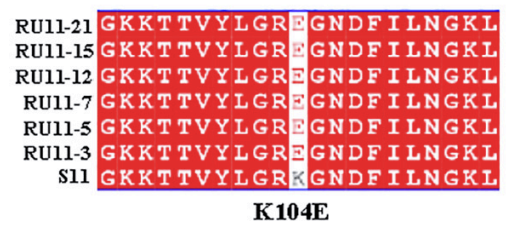

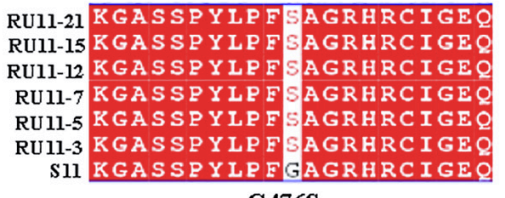

G476S
C

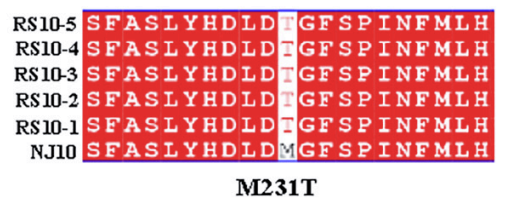

M231T

FIGURE 5 | Multiple sequence alignment of the CYP51 proteins in Botrytis cinerea sensitive parental isolates with that in (A) six other fungal species; (B) six resistant mutants (RU-mutants) generated from UV irradiation of conidia; (C) five resistant mutants (RS-mutants) acquired from the spontaneous selection of conidia. S11 and NJ10 correspond to the wild-type parental isolates. 


\section{Cross-Resistance}

For the 11 pyrisoxazole-resistant mutants and 11 sensitive field isolates tested, there was no correlation between sensitivity to pyrisoxazole and that to iprodione, procymidone, diethofencarb, fluazinam, pyrimethanil, or fludioxonil (Figures 4A-F). A positive correlation was observed between sensitivity to pyrisoxazole and that to DMIs tebuconazole $(\rho=0.82, P<0.0001)$ and prochloraz $(\rho=0.70, P=0.0002)$ (Figures 4G,H).

\section{Molecular Analysis of the CYP51 Gene in B. cinerea}

The CYP51 genes of the pyrisoxazole-resistant mutants and their parental isolates were cloned and sequenced (GenBank accession numbers: MT430873 for the sensitive isolate S11, MT430874 for the RU-mutant, MT430875 for the sensitive isolate NJ10, and MT430876 for the RS-mutant). An annotated alignment of CYP51 protein for several fungal species was shown in Figure 5A, and the ZtCYP51 sequence from Zymoseptoria tritici (accession number AY253234) was used as the archetype protein to unify the labeling of amino acids in fungicide target proteins (Figure 5A; Mair et al., 2016). Multiple sequence alignment revealed a two-point mutation, at amino acid positions 104 and 476 in all RU-mutants (Figure 5B), and a point mutation at amino acid position 231 in RS-mutants (Figure 5C). For the resistant mutants acquired from UV irradiation, lysine was substituted for glutamic acid at codon 104 (K104E), and glycine was substituted for serine at codon 476 (G476S). Methionine was substituted for threonine at codon 231 (M231T) for the mutants acquired from spontaneous selection (Figures 5B,C). The expression level of CYP51 gene was further determined, with and without pyrisoxazole treatment. It is found that the expression level of CYP51 was significantly induced by pyrisoxazole in the resistant mutants. It increased by 1.5-2.4-fold in RU-mutants compared to its parental wild-type isolate S11; and 2.2-3.2-fold in RS-mutants compared to NJ10 (Figure 6).

\section{Analysis of the Affinity Between the Mutation Positions and Pyrisoxazole}

Models were built for pyrisoxazole docking into the CYP51 binding pocket with the following mutations: K104E, G476S, and M231T. The docking scores of these predicted models are shown in Figure 7A. The model for the wild-type indicated that there were seven electrostatic interactions between CYP51 and pyrisoxazole (Figure 7B). The amino acid mutation G476S caused the migration of pyrisoxazole binding sites in the CYP51 and thereby led to the loss of four electrostatic interactions (Figure 7C). The docking score decreased from approximately $6.19-5.33$ for this G476S mutation (Figure 7A). Two electrostatic interactions disappeared with the M231T mutation (Figure 7D). As a result, the docking score changed from 6.19 for M231 and to 5.72 for T231 (Figure 7A). No change was found with the K104E mutation, which is also reflected by the unchanged score (Figure 7E).

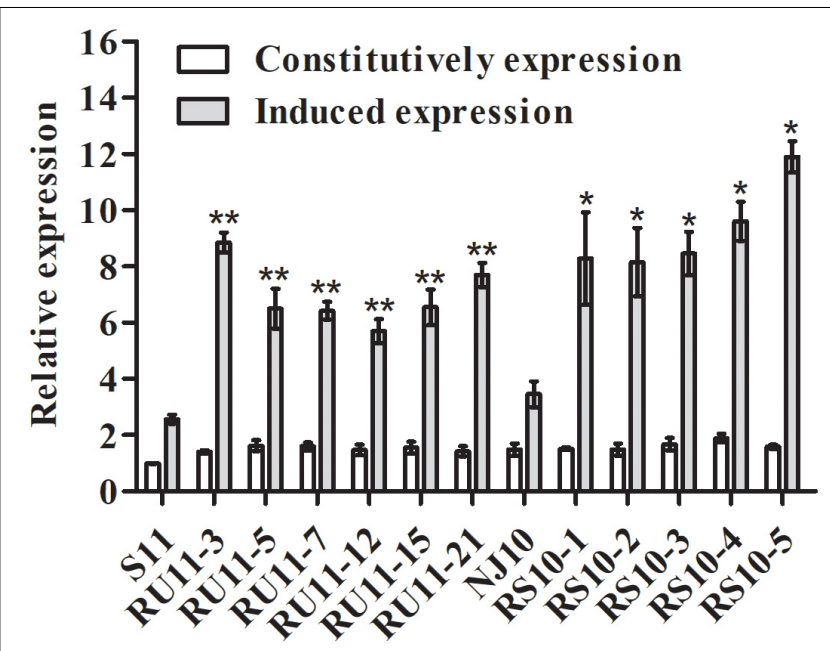

FIGURE 6 | Constitutive and fungicide-induced expression of CYP51 from pyrisoxazole resistant Botrytis cinerea mutants and the corresponding sensitive parental isolates $\mathrm{S} 11$ and NJ10. Relative expression of CYP51 was calculated by the $2^{-\Delta \Delta \mathrm{Ct}}$ method with the actin gene as reference. Expression in each isolate was relative to the expression of isolate S11. Columns and bars indicate mean \pm SD for replicates. An asterisk indicates significant differences between each pyrisoxazole-resistant isolate and its parental sensitive isolate based on an unpaired Student's $t$-test with the $P$-values marked $\left({ }^{\star} P<0.05 ;{ }^{* *} P<0.01\right)$

\section{DISCUSSION}

In this study, we established the baseline sensitivity of B. cinerea to pyrisoxazole using isolates from nine provinces in China, which represents the first step in monitoring and managing the development of fungicide resistance in the field (Russell, 2004). Given that the isolates were collected before pyrisoxazole was widely applied to fields in China, the $\mathrm{EC}_{50}$ values obtained provide a very accurate measure of the baseline sensitivity of B. cinerea to pyrisoxazole in this context. Zhu et al. (2016) determined the sensitivity of $B$. cinerea to pyrisoxazole from Liaoning province. As the isolates used in the present study were collected from the northern, central, and southern regions of China, the results can be used to provide a baseline for monitoring changes in the sensitivity of $B$. cinerea populations to pyrisoxazole in China. The low $\mathrm{EC}_{50}$ values (mean: 0.057 $\mu \mathrm{g} / \mathrm{ml}$ ) in this study were consistent with the previous report with the mean $\mathrm{EC}_{50}$ of $0.068 \mu \mathrm{g} / \mathrm{ml}$ (Zhu et al., 2016), and these provide strong evidence of no pyrisoxazole-resistant subpopulations existing in wild populations of $B$. cinerea. Moreover, the intrinsic activity of pyrisoxazole on $B$. cinerea was higher than most DMI fungicides, such as teuconazole used in the current study, as well as previous reported propiconazole and triflumizole (Markoglou and Ziogas, 2002; Song et al., 2016). In detail, the activity is about 5 or 10 times greater compared to teuconazole, or triflumizole, respectively. In addition, it showed a similar intrinsic activity with pyrifenox to $B$. cinerea (Hayashi et al., 2002). It is speculated that there may be some difference in the binding of DMIs in CYP51 protein of B. cinerea. 
A

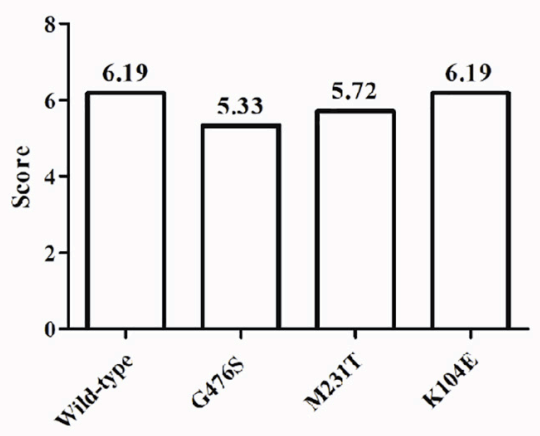

B

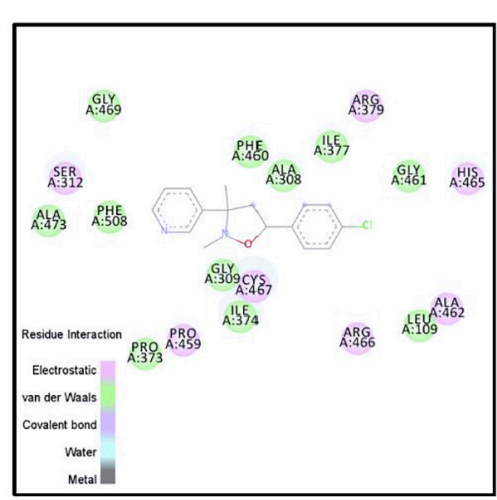

C

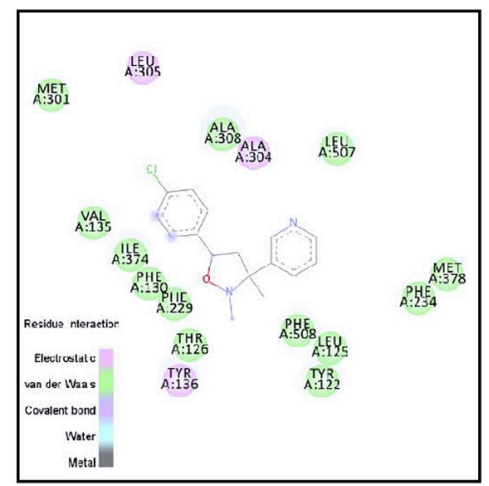

D

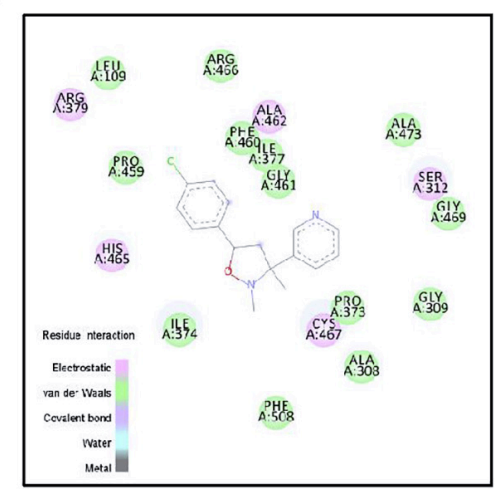

E

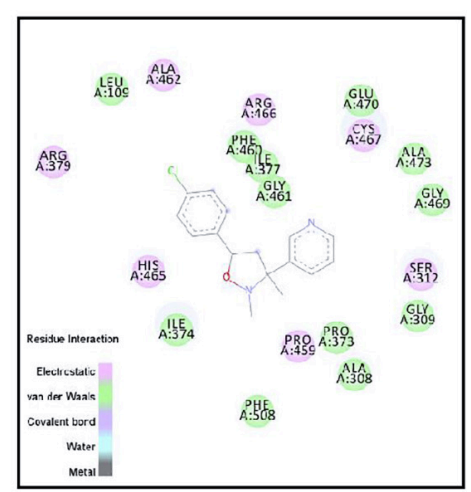

FIGURE 7 | Docking of pyrisoxazole in the modeled binding pockets of CYP51 in Botrytis cinerea. The structure of B. cinerea was modeled using the template of 5HS1 from Saccharomyces cerevisiae by the online Swiss-model software. (A) Total scores of pyrisoxazole docked into the CYP51 binding site of B. cinerea wild-type and mutated models; (B-E) represent the binding pockets of pyrisoxazole in the wild-type CYP51 (B), or with mutation G476S (C), M231T (D), or K104E (E) of B. cinerea.

No mutants were obtained from mycelium of $B$. cinerea. The mutation frequency from UV irradiation and spontaneous selection of conidia was $6.5 \times 10^{-9}$, and $5.0 \times 10^{-9}$, respectively. This low mutation frequency is in contrast to a previous study reporting frequent development of $Z$. tritici mutants resistant to DMI fungicides via spontaneous selection at a relatively high rate of about $10^{-4}$ (Zwiers et al., 2002). Consistent with $B$. cinerea, no pyrisoxazole-resistant mutants were obtained by spontaneous selection in the study of M. fructicola, and the average mutation frequency from the conidia of $M$. fructicola exposed to UV irradiation under pyrisoxazole treatment was $8.3 \times 10^{-10}$ (Chen et al., 2015). The very low frequency at which $B$. cinerea and $M$. fructicola generate pyrisoxazole-resistant mutants is mirrored by the fact that mutants have not been observed in fields sprayed with DMI fungicides multiple times or over several years. However, the average mutation frequency under pyrisoxazole treatment from the mycelium of $M$. fructicola was much higher, indicating that there is still the possibility to obtain mutants from $B$. cinerea mycelium. In the future work, more fungicide concentrations could be used for the screening of pyrisoxazole-resistant mutants.

On fungicide-treated tomato leaves, presumably the mutants with the lowest RF values are more difficult to control compared with sensitive isolates (Figure 2), indicating that reduced sensitivity of $B$. cinerea isolates to pyrisoxazole did occur. A comparison of the biological characteristics with the parental isolate indicated that there was a significant fitness penalty for most mutants, suggesting the spread of resistant mutants may be affected in the field. This was confirmed by the competitive ability test in which most of the resistant mutants showed a substantial drop in the observed frequency of pyrisoxazole-resistant isolates (Figure 3). However, some mutants bearing the same mutation in the target protein, such as RS10-1, showed an unimpaired fitness and even a higher competitive ability than its parent NJ10. It could be explained that some mutations might alter other areas of the genome as fitness penalty is not necessarily due to the mutations in the target CYP51 protein. Given the mutation frequency and cross-resistance results, the resistance risk of $B$. cinerea to pyrisoxazole may be considered to be low. Considering that the mutant RS10-1 still showed a good fitness and the control efficacy was clearly reduced when inoculating plants with these resistant mutants, it indicated that if such a mutation arises in field populations of $B$. cinerea, they could also possibly survive in the field. Therefore, on one hand, it is advisable to closely monitor any sensitivity changes to pyrisoxazole in $B$. cinerea populations in the field; on the other hand, more mutants with other phenotype and fitness 
should be obtained to further optimize this conclusion of resistance risk.

We found strong positive cross-resistance between pyrisoxazole and two DMIs in the mutants with different chemistries, and previous study also revealed cross-resistance between pyrisoxazole and propiconazole in $M$. fructicola mutants (Chen et al., 2015). Cross-resistance was not found between DMI and non-DMI fungicides in the current study. This is consistent with the cross-resistance reports on $M$. fructicola and S. sclerotiorum (Chen et al., 2015; Duan et al., 2018b). The efficacy of different commonly used fungicides has been decreased by the development of resistant $B$. cinerea isolates (as mentioned in "Introduction" section). Therefore, pyrisoxazole can be used in rotation for better management of gray mold. Mixtures of pyrisoxazole and the protective fungicide chlorothalonil or thiram have been reported to be highly effective for the control of B. cinerea (Shao et al., 2006). This can lower the selection pressure to slow down DMI resistance development.

Point mutations in the CYP51 protein and over-expression of the CYP51 gene are two main determinants of DMI resistance. The third hypothesis is resulted from over-expression of transporter genes, which is usually indicated by different spectrum of cross-resistance in resistant mutants depend upon the transporter involved (Hayashi et al., 2001; Ma and Michailides, 2005). No cross-resistance was found between DMIs and six non-DMIs in the mutants, it indicated that increased expression of membrane-bound transporters was not the main reason for the fungicide resistance and more kinds of fungicides could be used to explain this issue in the future. In this study, we firstly cloned and characterized the target gene CYP51 for B. cinerea and three point mutations K104E, G476S, M231T, were found in resistant B. cinerea mutants. Previous studies demonstrated that point mutation G461S in the MfCYP51 protein (corresponds to G476S in the reference ZtCYP51 sequence) is associated with tebuconazole resistance in M. fructicola populations in Brazil (Lichtemberg et al., 2017). Fujimura et al. (2016) listed the same mutation in Podosphaera xanthii resistant to DMI fungicides. Similar mutation was also reported in Pyrenopeziza brassicae with reduced tebuconazole sensitivity (Carter et al., 2014). This indicates these point mutations, especially the G476S mutation detected in the current study, might play roles in the resistance to pyrisoxazole of $B$. cinerea. Then, we found that the induced expression level of CYP51 increased in the resistant isolates when exposed to pyrisoxazole (Figure 6). Therefore, it indicated that point mutations in the CYP51 protein and the increased expression of the CYP51 gene both appeared to mediate the pyrisoxazole resistance of $B$ cinerea.

The point mutations could change the conformation of the binding pocket in $14 \alpha$-demethylase and reduce its potential to bind DMI fungicides (Sionov et al., 2012; Zhang et al., 2017; Qian et al., 2018). Molecular docking was used to explore the conformation change in the binding pocket of CYP51 of B cinerea, with or without point mutations. As expected, mutation G476S in CYP51 changed the conformation of pyrisoxazole in the binding pocket, and G476S and M231T mutations both led to the loss of electrostatic interactions, indicating these two mutations contributed to pyrisoxazole resistance the $B$ cinerea. In addition, the score of molecular docking decreased less than in the RS-mutants with M231T mutation, which may be related to the higher induced expression level of CYP51 in such mutants. According to our knowledge, this is the first report of M231T mutation on CYP51 protein in the DMI-resistant mutants, which needs further verification in the following work. Mutation K104E did not affect the binding of BcCYP51 and pyrisoxazole, and this amino acid position was also not conversed in different fungal species as shown in Figure 6A, suggesting it might be a linkage mutation with G476S. Similarly, a combined mutation at codons 103 and 157 in FgCYP51 was observed in $F$. graminearum metconazole-resistant mutants (Duan et al., 2018a).

In conclusion, baseline sensitivity using $110 \mathrm{~B}$. cinerea isolates collected from nine provinces in China was established in this present study. As pyrisoxazole showed a high intrinsic activity on $B$. cinerea and no cross-resistance was found between pyrisoxazole and non-DMI fungicides, it indicated that pyrisoxazole can be used for better management of gray mold. Molecular docking models were used to predict how the mutations in the CYP51 binding pocket alter the binding of DMIs, suggesting that the G476S and M231T mutations combined with induced expression of the target gene appeared to mediate pyrisoxazole resistance of $B$ cinerea. These results will be important for the control of the high-risk pathogen $B$. cinerea and may help in the development of more effective fungicides for disease management.

\section{DATA AVAILABILITY STATEMENT}

All datasets generated for this study are included in the article/Supplementary Material.

\section{AUTHOR CONTRIBUTIONS}

$\mathrm{CZ}$ and $\mathrm{XL}$ contributed to the conception and design of the study. CZ, MI, ML, ZL, and HG performed the experiments. $\mathrm{CZ}, \mathrm{XL}, \mathrm{HD}$, and $\mathrm{SZ}$ analyzed the data. $\mathrm{CZ}$ wrote the first draft of the manuscript. XL supervised the study and revised the manuscript critically. All authors contributed to the revision of this manuscript.

\section{FUNDING}

This study was supported by the National Key Research and Development Program of China (No. 2016YFD0201003), and also partially supported by the National High Technology Research and Development Program of China (No. 2012AA101502). 


\section{ACKNOWLEDGMENTS}

We thank the Laboratory of Fungicide Pharmacology and Pathogen Resistance at China Agricultural University for support in this work.

\section{REFERENCES}

Albertini, C., Thebaud, G., Fournier, E., and Leroux, P. (2002). Eburicol $14 \alpha-$ demethylase gene (CYP51) polymorphism and speciation in Botrytis cinerea. Mycol. Res. 106, 1171-1178. doi: 10.1017/s0953756202006561

Bardas, G. A., Veloukas, T., Koutita, O., and Karaoglanidis, G. S. (2010). Multiple resistance of Botrytis cinerea from kiwifruit to SDHIs, QoIs and fungicides of other chemical groups. Pest Manag. Sci. 66, 967-973. doi: 10.1002/ps.1968

Birchmore, R. J., Williams, R. J., Russell, P. E., and Lagouarde, P. (1996). A baseline for the sensitivity of Botrytis cinerea to pyrimethanil. Brighton Crop Prot. Conf. Pests Dis. 2, 713-718.

Cai, M., Lin, D., Chen, L., Bi, Y., Xiao, L., and Liu, X. L. (2015). M233I mutation in the $\beta$-tubulin of Botrytis cinerea confers resistance to zoxamide. Sci. Rep. U.K. 5:16881.

Carter, H. E., Fraaije, B. A., West, J., Kelly, S. L., Mehl, A., Shaw, M. W., et al. (2014). Alterations in the predicted regulatory and coding regions of the sterol $14 \alpha$-demethylase gene (CYP51) confer decreased azole sensitivity in the oilseed rape pathogen Pyrenopeziza brassicae. Mol. Plant Pathol. 15, 513-522. doi: 10.1111/mpp.12106

Chen, F., Lin, D., Wang, J., Li, B., Duan, H., Liu, J., et al. (2015). Heterologous expression of the Monilinia fructicola CYP51 (MfCYP51) gene in Pichia pastoris confirms the mode of action of the novel fungicide, SYP-Z048. Front. Microbiol. 6:457. doi: 10.3389/fmicb.2015.00457

Chen, F. P., Fan, J. R., Zhou, T., Liu, X. L., Liu, J. L., and Schnabel, G. (2012). Baseline sensitivity of Monilinia fructicola from China to the DMI fungicide SYP-Z048 and analysis of DMI-resistant mutants. Plant Dis. 96, 416-422. doi: 10.1094/pdis-06-11-0495

Chen, S. N., Luo, C. X., Hu, M. J., and Schnabel, G. (2016). Fitness and competitive ability of Botrytis cinerea isolates with resistance to multiple chemical classes of fungicides. Phytopathology 106, 997-1005. doi: 10.1094/phyto-02-16-0061-r

Chi, M. H., Park, S. Y., and Lee, Y. H. (2009). A quick and safe method for fungal DNA extraction. Plant Pathol. J. 25, 108-111. doi: 10.5423/ppj.2009.25.1.108

Cools, H. J., Hawkins, N. J., and Fraaije, B. A. (2013). Constraints on the evolution of azole resistance in plant pathogenic fungi. Plant Pathol. 62, 36-42. doi: 10.1111/ppa.12128

Duan, Y., Li, M., Zhao, H., Lu, F., Wang, J., and Zhou, M. (2018a). Molecular and biological characteristics of laboratory metconazole-resistant mutants in Fusarium graminearum. Pestic. Biochem. Phys. 152, 55-61. doi: 10.1016/j. pestbp.2018.08.011

Duan, Y., Li, T., Xiao, X., Wu, J., Li, S., Wang, J., et al. (2018b). Pharmacological characteristics of the novel fungicide pyrisoxazole against Sclerotinia sclerotiorum. Pestic. Biochem. Phys. 149, 61-66. doi: 10.1016/j. pestbp.2018.05.010

Elad, Y., Williamson, B., Tudzynski, P., and Delen, N. (2007). "Botrytis spp. and diseases they cause in agricultural systems-an introduction," in Botrytis: Biology, Pathology and Control, eds Y. Elad, B. Williamson, P. Tudzynski, and N. Delen (Dordrecht: Springer), 1-8. doi: 10.1007/978-1-4020-2626-3_1

Fan, F., Hamada, M. S., Li, N., Li, G. Q., and Luo, C. X. (2017). Multiple fungicide resistance in Botrytis cinerea from greenhouse strawberries in hubei province. China. Plant Dis. 101, 601-606. doi: 10.1094/pdis-09-16-1227-re

Fan, X., Zhang, J., Yang, L., Wu, M., Chen, W., and Li, G. (2015). Development of PCR-based assays for detecting and differentiating three species of Botrytis infecting broad bean. Plant Dis. 99, 691-698. doi: 10.1094/pdis-07-14-0701-re

Fernández-Ortuño, D., Chen, F., and Schnabel, G. (2012). Resistance to pyraclostrobin and boscalid in Botrytis cinerea isolates from strawberry fields in the carolinas. Plant Dis. 96, 1198-1203. doi: 10.1094/pdis-12-11-1049-re

Fujimura, M., Banno, S., Kamei, M., Ishigami, Y., and Tsukada, Y. (2016). Detection and monitoring of fungicide resistance in plant pathogens using pyrosequencing. Jpn. J. Pestic. Sci. 41, 78-87. doi: 10.1584/jpestics.W15-36

\section{SUPPLEMENTARY MATERIAL}

The Supplementary Material for this article can be found online at: https://www.frontiersin.org/articles/10.3389/fmicb. 2020.01396/full\#supplementary-material

Hahn, M. (2014). The rising threat of fungicide resistance in plant pathogenic fungi: Botrytis as a case study. J. Chem. Biol. 7, 133-141. doi: 10.1007/s12154014-0113-1

Hayashi, K., Schoonbeek, H., and De Waard, M. A. (2002). Expression of the $\mathrm{ABC}$ transporter $\mathrm{BcatrD}$ from Botrytis cinerea reduces sensitivity to sterol demethylation inhibitor fungicides. Pestic. Biochem. Phys. 73, 110-121. doi: 10.1016/s0048-3575(02)00015-9

Hayashi, K., Schoonbeek, H. J., Sugiura, H., and De Waard, M. A. (2001). Multidrug resistance in Botrytis cinerea associated with decreased accumulation of the azole fungicide oxpoconazole and increased transcription of the $\mathrm{ABC}$ transporter gene BcatrD. Pestic. Biochem. Phys. 70, 168-179. doi: 10.1006/pest. 2001.2548

Jain, A. N. (1996). Scoring noncovalent protein-ligand interactions: a continuous differentiable function tuned to compute binding affinities. J. Comput. Aid. Mol. Des. 10, 427-440. doi: 10.1007/bf00124474

Jain, A. N. (2003). Surflex: fully automatic flexible molecular docking using a molecular similarity-based search engine. J. Med. Chem. 46, 499-511. doi: $10.1021 /$ jm020406h

Kretschmer, M., and Hahn, M. (2008). Fungicide resistance and genetic diversity of Botrytis cinerea isolates from a vineyard in Germany. J. Plant Dis. Protec. 115, 214-219. doi: 10.1007/bf03356266

Kretschmer, M., Leroch, M., Mosbach, A., Walker, A. S., Fillinger, S., Mernke, D., et al. (2009). Fungicide-driven evolution and molecular basis of multidrug resistance in field populations of the grey mould fungus Botrytis cinerea. PLoS Pathog. 5:e1000696. doi: 10.1371/journal.ppat.1000696

Kumari, S., Tayal, P., Sharma, E., and Kapoor, R. (2014). Analyses of genetic and pathogenic variability among Botrytis cinerea isolates. Microbiol. Res. 169, 862-872. doi: 10.1016/j.micres.2014.02.012

Leroux, P. (2007). "Chemical control of Botrytis and its resistance to chemical fungicides," in Botrytis: Biology, Pathology and Control, eds Y. Elad, B. Williamson, P. Tudzynski, and N. Delen (Dordrecht: Springer), 195-222. doi: 10.1007/978-1-4020-2626-3_12

Leroux, P., and Walker, A. S. (2013). Activity of fungicides and modulators of membrane drug transporters in field strains of Botrytis cinerea displaying multidrug resistance. Eur. J. Plant Pathol. 135, 683-693. doi: 10.1007/s10658012-0105-3

Lichtemberg, P. S., Luo, Y., Morales, R. G., Muehlmann-Fischer, J. M., Michailides, T. J., and May De Mio, L. L. (2017). The point mutation G461S in the MfCYP51 gene is associated with tebuconazole resistance in Monilinia fructicola populations in Brazil. Phytopathology 107, 1507-1514. doi: 10.1094/ phyto-02-17-0050-r

Liu, J. L., Si, N. G., Chen, L., Zhang, D. M., and Zhang, Z. J. (2004). Biological activity against tomato leaf mold and application of a novel fungicide, SYP-Z048 (III). Chin. J. Pestic. 43, 103-105.

Liu, S., Che, Z., and Chen, G. (2016). Multiple-fungicide resistance to carbendazim, diethofencarb, procymidone, and pyrimethanil in field isolates of Botrytis cinerea from tomato in henan province, China. Crop Prot. 84, 56-61. doi: 10.1016/j.cropro.2016.02.012

Livak, K. J., and Schmittgen, T. D. (2001). Analysis of relative gene expression data using real-time quantitative PCR and the 2- $\Delta \Delta \mathrm{CT}$ method. Methods 25, 402-408. doi: 10.1006/meth.2001.1262

Ma, Z., and Michailides, T. J. (2005). Advances in understanding molecular mechanisms of fungicide resistance and molecular detection of resistant genotypes in phytopathogenic fungi. Crop Prot. 24, 853-863. doi: 10.1016/j. cropro.2005.01.011

Mair, W., Lopez-Ruiz, F., Stammler, G., Clark, W., Burnett, F., Hollomon, D., et al. (2016). Proposal for a unified nomenclature for target-site mutations associated with resistance to fungicides. Pest Manag. Sci. 72, 1449-1459. doi: $10.1002 / \mathrm{ps} .4301$ 
Markoglou, A. N., and Ziogas, B. N. (2002). SBI-fungicides: fungicidal effectiveness and resistance in "Botrytis cinerea". Phytopathol. Mediterr. 41, 120-130.

Moyano, C., Gómez, V., and Melgarejo, P. (2004). Resistance to pyrimethanil and other fungicides in Botrytis cinerea populations collected on vegetable crops in Spain. J. Phytopathol. 152, 484-490. doi: 10.1111/j.1439-0434.2004. 00880.x

Myresiotis, C. K., Karaoglanidis, G. S., and Tzavella-Klonari, K. (2007). Resistance of Botrytis cinerea isolates from vegetable crops to anilinopyrimidine, phenylpyrrole, hydroxyanilide, benzimidazole, and dicarboximide fungicides. Plant Dis. 91, 407-413. doi: 10.1094/pdis-91-4-0407

Qian, H., Du, J., Chi, M., Sun, X., Liang, W., Huang, J., et al. (2018). The $\mathrm{Y} 137 \mathrm{H}$ mutation in the cytochrome $\mathrm{P} 450 \mathrm{FgCYP} 51 \mathrm{~B}$ protein confers reduced sensitivity to tebuconazole in Fusarium graminearum. Pest Manag. Sci. 74, 1472-1477. doi: 10.1002/ps.4837

Rosslenbroich, H. J., and Stuebler, D. (2000). Botrytis cinerea-history of chemical control and novel fungicides for its management. Crop Prot. 19, 557-561. doi: 10.1016/s0261-2194(00)00072-7

Russell, P. E. (2004). Sensitivity Baseline In Fungicide Resistance Research, And Management. Brussels: FRAC Press.

Samuel, S., Papayiannis, L. C., Leroch, M., Veloukas, T., Hahn, M., and Karaoglanidis, G. S. (2011). Evaluation of the incidence of the G143A mutation and cytb intron presence in the cytochrome bc-1 gene conferring QoI resistance in Botrytis cinerea populations from several hosts. Pest Manag. Sci. 67, 1029-1036. doi: 10.1002/ps.2226

Shao, J. X., Zhou, X. F., and Zhang, J. X. (2006). Field experimental results in controlling tomato gray mold with SYP-Z048 25\% EC. Agrochemicals 45, $488-490$.

Si, N. G., Zhang, Z. J., Liu, J. L., Li, Z. N., Zhang, D. M., Chen, L., et al. (2004a). Biological activity and application of a novel fungicide: SYP-Z048. Chin. J. Pestic. 43, 16-18.

Si, N. G., Zhang, Z. J., Liu, J. L., Li, Z. N., Zhan, D. M., Chen, L., et al. (2004b). Biological activity and application of a novel fungicide, SYP-Z048 (II). Chin. J. Pestic. 43, 61-63.

Sionov, E., Chang, Y. C., Garraffo, H. M., Dolan, M. A., Ghannoum, M. A., and Kwon-Chung, K. J. (2012). Identification of a Cryptococcus neoformans cytochrome P450 lanosterol 14 $\alpha$-demethylase (Erg11) residue critical for differential susceptibility between fluconazole/voriconazole and itraconazole/posaconazole. Antimicrob. Agents Chem. 56, 1162-1169. doi: 10. 1128/aac.05502-11
Song, Y., Xu, D., Lu, H., He, L., Chen, L., Shao, J., et al. (2016). Baseline sensitivity and efficacy of the sterol biosynthesis inhibitor triflumizole against Botrytis cinerea. Austr. Plant Pathol. 45, 65-72. doi: 10.1007/s13313-015-0384-1

Williamson, B., Tudzynski, B., Tudzynski, P., and van Kan, J. A. (2007). Botrytis cinerea: the cause of grey mould disease. Mol. Plant Pathol. 8, 561-580. doi: 10.1111/j.1364-3703.2007.00417.x

Yin, W. X., Adnan, M., Shang, Y., Lin, Y., and Luo, C. X. (2018). Sensitivity of Botrytis cinerea from nectarine/cherry in China to six fungicides and characterization of resistant isolates. Plant Dis. 102, 578.

Zhang, C., Diao, Y., Wang, W., Hao, J., Imran, M., Duan, H., et al. (2017). Assessing the risk for resistance and elucidating the genetics of Colletotrichum truncatum that is only sensitive to some DMI fungicides. Front. Microbiol. 8:1779. doi: $10.3389 /$ fmicb.2015.001779

Zhang, C. Q., Hu, J. L., Wei, F. L., and Zhu, G. N. (2009). Evolution of resistance to different classes of fungicides in Botrytis cinerea from greenhouse vegetables in eastern China. Phytoparasitica 37, 351-359. doi: 10.1007/s12600-009-0050-7

Zhang, Y., Zhou, Q., Tian, P., Li, Y., Duan, G., Li, D., et al. (2019). Induced expression of CYP51 associated with difenoconazole resistance in the pathogenic Alternaria sect. on potato in China. Pest Manag. Sci. 76, 1751-1760. doi: $10.1002 /$ ps.5699

Zhu, H., Huang, C. T., and Ji, M. S. (2016). Baseline sensitivity and control efficacy of pyrisoxazole against Botrytis cinerea. Eur. J. Plant Pathol. 146, 315-323. doi: 10.1007/s10658-016-0917-7

Zwiers, L. H., Stergiopoulos, L., Van Nistelrooy, J. G. M., and De Waard, M. A. (2002). ABC transporters and azole susceptibility in laboratory strains of the wheat pathogen Mycosphaerella graminicola. Antimicrob. Agents Chemother. 46, 3900-3906. doi: 10.1128/aac.46.12.3900-3906.2002

Conflict of Interest: The authors declare that the research was conducted in the absence of any commercial or financial relationships that could be construed as a potential conflict of interest.

Copyright () 2020 Zhang, Imran, Liu, Li, Gao, Duan, Zhou and Liu. This is an open-access article distributed under the terms of the Creative Commons Attribution License (CC BY). The use, distribution or reproduction in other forums is permitted, provided the original author(s) and the copyright owner(s) are credited and that the original publication in this journal is cited, in accordance with accepted academic practice. No use, distribution or reproduction is permitted which does not comply with these terms. 